\section{Watering Regime and Green Roof Substrate Design Affect Sedum Plant Growth}

\author{
Nicholaus D. VanWoert, ${ }^{1}$ D. Bradley Rowe, ${ }^{2}$ Jeffrey A. Andresen, ${ }^{3}$ \\ Clayton L. Rugh, ${ }^{4}$ and Lan Xiao ${ }^{5}$ \\ Michigan State University, East Lansing, MI 48824
}

Additional index words. ecoroof, evapotranspiration, extensive green roof, stonecrop, water management

\begin{abstract}
Green roofs are an increasingly common, environmentally responsible building practice in the United States and abroad. They represent a new and growing market for the horticulture field, but require vegetation tolerant of harsh environmental conditions. Historically, Sedum species have been the most commonly used plants because, with proper species selection, they are tolerant of extreme temperatures, high winds, low fertility, and a limited water supply. A greenhouse study was conducted to determine how water availability influences growth and survival of a mixture of Sedum spp. on a green roof drainage system. Results indicate that substrate volumetric moisture content can be reduced to $0 \mathrm{~m}^{3} \cdot \mathrm{m}^{-3}$ within 1 day after watering depending on substrate depth and composition. Deeper substrates provided additional growth with sufficient water, but also required additional irrigation because of the higher evapotranspiration rates resulting from the greater biomass. Over the 88 day study, water was required at least once every 14 days to support growth in green roof substrates with a $2-\mathrm{cm}$ media depth. However, substrates with a 6-cm media depth could do so with a watering only once every 28 days. Although vegetation was still viable after 88 days of drought, water should be applied at least once every 28 days for typical green roof substrates and more frequently for shallower substrates to sustain growth. The ability of Sedum to withstand extended drought conditions makes it ideal for shallow green roof systems.
\end{abstract}

Green roofs are an increasingly common, environmentally responsible building practice. Originally, modern-day green roofs were installed to replace lost green space (Herman, 2003). Today, however, green roof installations are driven by several environmental and economic forces (Herman, 2003; Liptan, 2003). They can reduce the heat load on buildings (Niachou et al., 2001), aid in reducing the urban heat island effect (Dimoudi and Nikolopoulou, 2003; Wong et al., 2003), reduce air and water pollution (Dramstad et al., 1996; Liesecke and Borgwardt, 1997), and reducestorm waterrunoff from the roof (Liesecke, 1998; Monterusso et al., 2004; VanWoert et al., 2005). In addition, Relf and Lohr (2003) indicated that numerous studies have documented the positive influence of plants on human well-being and reduced stress; there is no reason why green roofs would

Received for publication 9 Sept. 2004. Accepted for publication 7 Dec. 2004. This paper is a portion of a MS thesis submitted by Nicholaus D. VanWoert. Funding for this study was provided by Ford Motor Company, Dearborn, MI; ChristenDETROIT Roofing Contractors, Detroit, MI; Wolfgang Behrens Systementwicklung, $\mathrm{GmbH}$, Groß Ippener, Germany; and the Michigan Agricultural Experiment Station. Illustration by Marlene Cameron.

${ }^{1}$ Former graduate research assistant, Department of Horticulture.

${ }^{2}$ Associate professor, Department of Horticulture. ${ }^{3}$ Associate professor, Department of Geography.

${ }^{4}$ Assistant professor, Department of Crop and Soil Sciences.

${ }^{5}$ College of Agriculture and Natural Resources Statistical Consulting Center. moisture retention fabric layer, or 3 ) deep $=6 \mathrm{~cm}$ of media. from surrounding buildings.

Although several plant taxa have been Axplored for potential green roof utilizati Sedum (Boivin et al., 2001; Lassalle, 1998; Monterusso et al., 2005). Water use and drought tolerance among this genus have been well studied (Lee and Kim, 1994; Gravatt and Martin, 1992; Gurevitch et al., 1986; Ting, 1985). However, to our knowledge, only a few studies have examined plant water use while using green roof drainage systems (Kirschstein 1997a, 1997b; Lassalle, 1998). Lassalle (1998) studied the effects of substrate depth and substrate water holding capacity (WHC) on drought stress for three potential green roof plant species. Utilizing media depths between 2.5 and $15 \mathrm{~cm}$ in the study, Sedum album L. outperformed Festuca glauca Vill. and Chrysanthemum leucanthemum L. in all treatments concerning visual appearance under drought conditions.

Drought tolerant Sedum spp. are ideal for extensive green roofs due to their method of photosynthetic carbon metabolism and their ability to store water. All Sedum spp. are succulents, and are categorized as crassulacean acid metabolism (CAM) plants, one of three mechanisms for plant uptake of $\mathrm{CO}_{2}$. CAM plants have the ability to fix $\mathrm{CO}_{2}$ in the dark for later use in photosynthesis. By opening their stomata at night for the uptake of $\mathrm{CO}_{2}$, they limit water loss due to transpiration (Ting, 1985). Facultative CAM plants are a variation of CAM and are able to shift between $\mathrm{C}_{3}$ metabolism and CAM depending on soil moisture conditions (Lee and Kim, 1994; Ting, 1985). This ability to shift from one method of metabolism to the other is very beneficial when water becomes available to the plant (Borland and Griffiths, 1990). Several Sedum spp. possess the facultative CAM trait, including $S$. kamtschaticum Fisch. (Lee and Kim, 1994).

One key to survival under drought stress is water use efficiency (WUE), which is increased in CAM plants. Sedum spp. have been shown to have greater WUE values than most $\mathrm{C}_{3}$ and $\mathrm{C}_{4}$ plants (Gravatt and Martin, 1992). Staats and Klett (1995) found that $S$. acre L. required less irrigation to maintain a pleasing leaf color

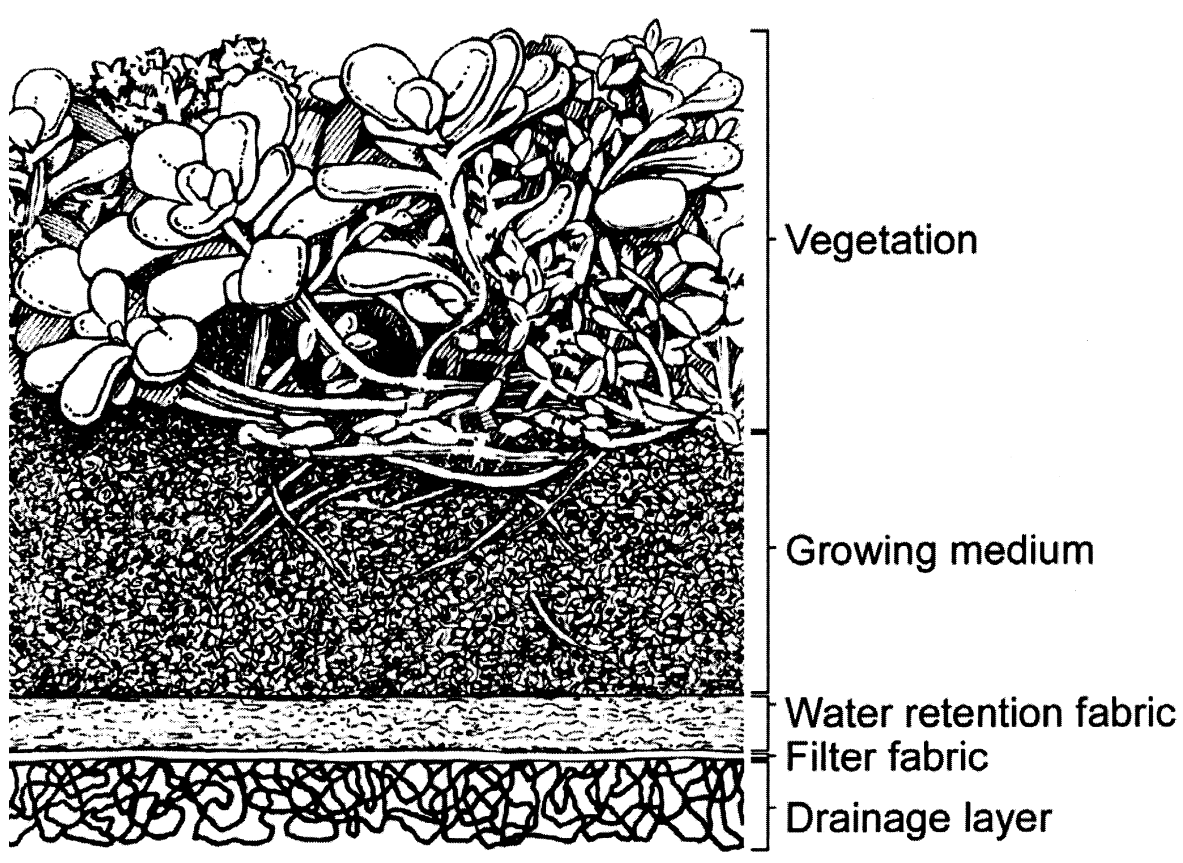

Fig. 1. Cross section of a representative extensive green roof system. Substrate treatments for this study were modified as either 1) shallow $=2 \mathrm{~cm}$ of media, 2) shallow + fabric $=2 \mathrm{~cm}$ of media with an extra

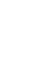

(n)

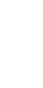

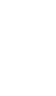

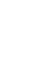


when compared with $\mathrm{C}_{3}$ and $\mathrm{C}_{4}$ plants. They also found that the quality of this species with no supplemental irrigation was almost as good as that of irrigated plants.

Some Sedum spp. are able to store extra water in their leaves and shoots. Teeri et al. (1986) showed that apical portions of $S$. rubrotinctum R.T. Clausen could survive at least two years without supplemental water in a greenhouse due to its ability to reallocate water to vital plant tissues. Kirschstein (1997b) studied the root water potential of Sedum and concluded that this mechanism also helps the plant survive periods of drought. Kirschstein (1997a) explained that the frequency of rain was more important to succulent plants than the total amount of rain because they are able to recover with only small amounts of moisture. After a period of drought in a greenhouse, many Sedum spp. recovered within one week of rehydration.

Although Sedum are ideal green roof plants in terms of drought tolerance, water availability is still one of the most limiting factors for green roofs (Dunnett and Nolan, 2004; Kirschstein, 1997a). Extensive systems generally rely on natural precipitation events, although irrigation systems are sometimes used during establishment or when plant health begins to decline. However, when extensive green roofs are designed for long-term sustainability, watering frequency is minimized during and after plant establishment. The presence of drought tolerant vegetation is essential for the longevity of an extensive green roof because of limited irrigation and shallow substrate depth $(3 \mathrm{~cm}-$ $10 \mathrm{~cm})$. Deeper substrates will usually provide greater water holding capacity to optimize plant growth, but the additional weight may require higher building construction costs to ensure structural stability.

Deeper substrates will result in faster substrate coverage (Durhman et al., 2004). Plant species, substrate depth, and the availability of water are all factors in determining the appropriate planting density of each species to achieve optimal green roof coverage in the desired timeframe. Although, maintaining vigorous, healthy green growth throughout a drought period will maintain a roof's aesthetic appeal, it does not necessarily influence the functional qualities of the roof. Rowe et al. (2003) compared stormwater retention on vegetated, substrate only, and conventional roofs with a gravel ballast. There were no significant differences in stormwater retention between the roofs that were vegetated and those that were covered with substrate only. This suggests that the main factor for water retention is the physical properties of the media.

If the green roof industry is to continue to grow in the United States, quantifiable data on how water availability influences growth and survival of Sedum is needed to aid green roof managers in making irrigation decisions for both establishment and maintenance of green roofs. Therefore, a greenhouse study was conducted under controlled conditions to determine the minimum irrigation requirements for survival and maintenance of a mixture of Sedum spp. on a green roof drainage system.
The results of this experiment will be instructive for future water management decisions through both the propagation and functional stages of extensive green roofs.

\section{Materials and Methods}

Potted green roof system design. Plastic pots $(11 \times 11 \times 12 \mathrm{~cm}$ deep $)$ were filled with one of three substrate types, all of which included a green roof drainage layer (XF108) and vegetation carrier (XF301) (Wolfgang Behrens Systementwicklung, GmbH, Groß Ippener, Germany) at the Plant Science Greenhouses at Michigan State University, East Lansing, Mich. The drainage layer consists of a geotextile fabric with nylon coils attached on the underside and has a total thickness of about $1.5 \mathrm{~cm}$. The vegetation carrier was placed above the drainage layer. It included a recycled synthetic fiber fabric used for water retention sewn to an inverted version of the drainage layer that held media and vegetation. The water retention fabric holds up to $800 \mathrm{~g} \cdot \mathrm{m}^{-2}$ of water and is about $0.75 \mathrm{~cm}$ thick. It is composed of a recycled synthetic fiber mixture consisting of polyester, polyamide, polypropylene, and acrylic fibers. Total thickness of the drainage layer and vegetation carrier is about $3.75 \mathrm{~cm}$. The assembled system allows excess water from the retention fabric and planting media to drain through the nylon coils and exit the pot. A representative extensive green roof system similar to the one used for this study is shown in Fig. 1.

Growing medium. The growing medium consisted of $40 \%$ heat-expanded slate (gradation 3 to $5 \mathrm{~mm}$ ) (PermaTill, Carolina Stalite Company, Salisbury, N.C.), 40\% United States GolfAssociation(USGA) grade sand (Osburn Industries, Taylor, Mich.), 10\% Michigan Peat (Osburn Industries, Taylor, Mich.), 5\% dolomite(Osburn Industries, Taylor, Mich.), 3.33\% composted yard waste (Kalamazoo Landscape Supplies, Kalamazoo, Mich.), and 1.67\% composted poultry litter(Herbruck's, Saranac, Mich.) by volume. At time of planting, electri- cal conductivity (EC) and $\mathrm{pH}$ of the medium were $3.29 \mathrm{mmho}^{\circ} \mathrm{cm}^{-1}$ and 7.9 , respectively. All treatments had $100 \mathrm{~g} \cdot \mathrm{m}^{-2}$ of Nutricote type 100 , $20 \mathrm{~N}-7 \mathrm{P}_{2} \mathrm{O}_{5}-10 \mathrm{~K}_{2} \mathrm{O}$ controlled release fertilizer (Agrivert, Webster, Texas) hand-applied at the time of planting.

Plant material. A seed mixture of seven Sedum spp. was sown on 14 Jan. 2003. The mixture contained seed of $S$. acre L., S. album L., S. kamtschaticum ellacombianum Fisch., $S$. pulchellum Michx., S. reflexum L., $S$. spurium Bieb. 'Coccineum', and S. spurium Bieb. 'Summer Glory', at a rate of $0.14 \mathrm{~g} \cdot \mathrm{m}^{-2}$ for each species. All seed was obtained from Jelitto Staudensamen, GmbH (Schwarmstedt, Germany). Due to its extremely small size, seed was mixed in dry sand prior to application to ensure even distribution within each pot. In total, 83 pots of each substrate type (249 total pots) were established for an 85 -d period prior to use in the actual experiment.

Natural lighting in the greenhouse was supplemented with 400-W incandescent lighting (Philips Lighting Co., Somerset, N.J.) for a 16-h photoperiod. Average light meter (LI-250; LI-COR, Inc., Lincoln, Nebr.) measurements at plant height were $338.4 \mu \mathrm{mol} \cdot \mathrm{s}^{-1} \cdot \mathrm{m}^{-2}$ on a selected representative cloudy day and 897.1 $\mu \mathrm{mol} \cdot \mathrm{s}^{-1} \cdot \mathrm{m}^{-2}$ on a selected representative sunny day. Air temperature was controlled by a thermostat set at $21 \pm 1{ }^{\circ} \mathrm{C}$.

Once the plants were established, the study commenced on 10 Apr. 2003. At this time a representative sample of 33 pots from each substrate type (99 total pots) was selected on the first day of the study. Shoots from each pot in the representative sample were harvested and dried for $72 \mathrm{~h}$ at $60{ }^{\circ} \mathrm{C}$ to establish an initial mean shoot biomass dry weight.

Substrate and watering regime factors. Three substrate types were studied: 1 ) shallow $=80 \mathrm{~mL}$ of media ( $2 \mathrm{~cm}$ depth); 2$)$ shallow + fabric $=80 \mathrm{~mL}$ of media $(2 \mathrm{~cm}$ depth $)$ with an extra moisture retention fabric layer capable of retaining $1200 \mathrm{~g} \cdot \mathrm{m}^{-2}$ of water(XF158, Wolfgang Behrens Systementwicklung, $\mathrm{GmbH}$ ); and 3) deep $=300 \mathrm{~mL}$ of media $(6 \mathrm{~cm}$ depth).

Table 1. Mean shoot dry weight accumulation (g) for each treatment over the course of the study. Values are treatment means of substrate types-1) shallow $=2 \mathrm{~cm}$ of media, 2) shallow + fabric $=2 \mathrm{~cm}$ of media with an extra moisture retention fabric layer, and 3) deep $=6 \mathrm{~cm}$ of media-within each watering regime.

\begin{tabular}{lccccc}
\hline & \multicolumn{5}{c}{ Days between watering (DBW) } \\
\cline { 2 - 6 } Substrate & 2 & 7 & 14 & 28 & 88 \\
Shallow & $1.82 \mathrm{~b} \mathrm{~A}^{\mathrm{z}}$ & $0.46 \mathrm{~b} \mathrm{~B}$ & $-0.04 \mathrm{~b} \mathrm{~B}$ & $0.09 \mathrm{a} \mathrm{B}$ & $-0.06 \mathrm{a} \mathrm{B}$ \\
Shallow + fabric & $2.68 \mathrm{~b} \mathrm{~A}$ & $0.63 \mathrm{~b} \mathrm{~B}$ & $0.27 \mathrm{ab} \mathrm{B}$ & $0.13 \mathrm{a} \mathrm{B}$ & -0.01 a B \\
Deep & $5.54 \mathrm{a} \mathrm{A}$ & $2.63 \mathrm{a} \mathrm{B}$ & $1.30 \mathrm{a} \mathrm{C}$ & $0.99 \mathrm{a} \mathrm{C}$ & $-0.46 \mathrm{a} \mathrm{D}$ \\
\hline
\end{tabular}

${ }^{\mathrm{z}}$ Means followed by different lowercase letters (within columns) or uppercase letters (within rows) are significantly different $(P \leq 0.05)$.

Table 2. Percentage increase in shoot dry weight for each treatment over the course of the study. Values are treatment means of substrate types - 1) shallow $=2 \mathrm{~cm}$ of media, 2) shallow + fabric $=2 \mathrm{~cm}$ of media with an extra moisture retention fabric layer, and 3) deep $=6 \mathrm{~cm}$ of media - within each watering regime.

\begin{tabular}{lcrrrr}
\hline & \multicolumn{5}{c}{ Days between watering (DBW) } \\
\cline { 2 - 5 } Substrate & 2 & 7 & 14 & 28 & 88 \\
\hline Shallow & $674 \mathrm{a} \mathrm{A}^{\mathrm{z}}$ & $170 \mathrm{a} \mathrm{B}$ & $-15 \mathrm{~b} \mathrm{~B}$ & $33 \mathrm{a} \mathrm{B}$ & -22 a B \\
Shallow + fabric & $724 \mathrm{a} \mathrm{A}$ & $170 \mathrm{a} \mathrm{B}$ & $73 \mathrm{a} \mathrm{B}$ & $35 \mathrm{a} \mathrm{B}$ & -3 a B \\
Deep & $374 \mathrm{~b} \mathrm{~A}$ & $178 \mathrm{a} \mathrm{B}$ & $88 \mathrm{a} \mathrm{C}$ & $67 \mathrm{a} \mathrm{C}$ & -31 a D
\end{tabular}

${ }^{\mathrm{z}}$ Means followed by different lowercase letters (within columns) or uppercase letters (within rows) are significantly different $(P \leq 0.05)$ 


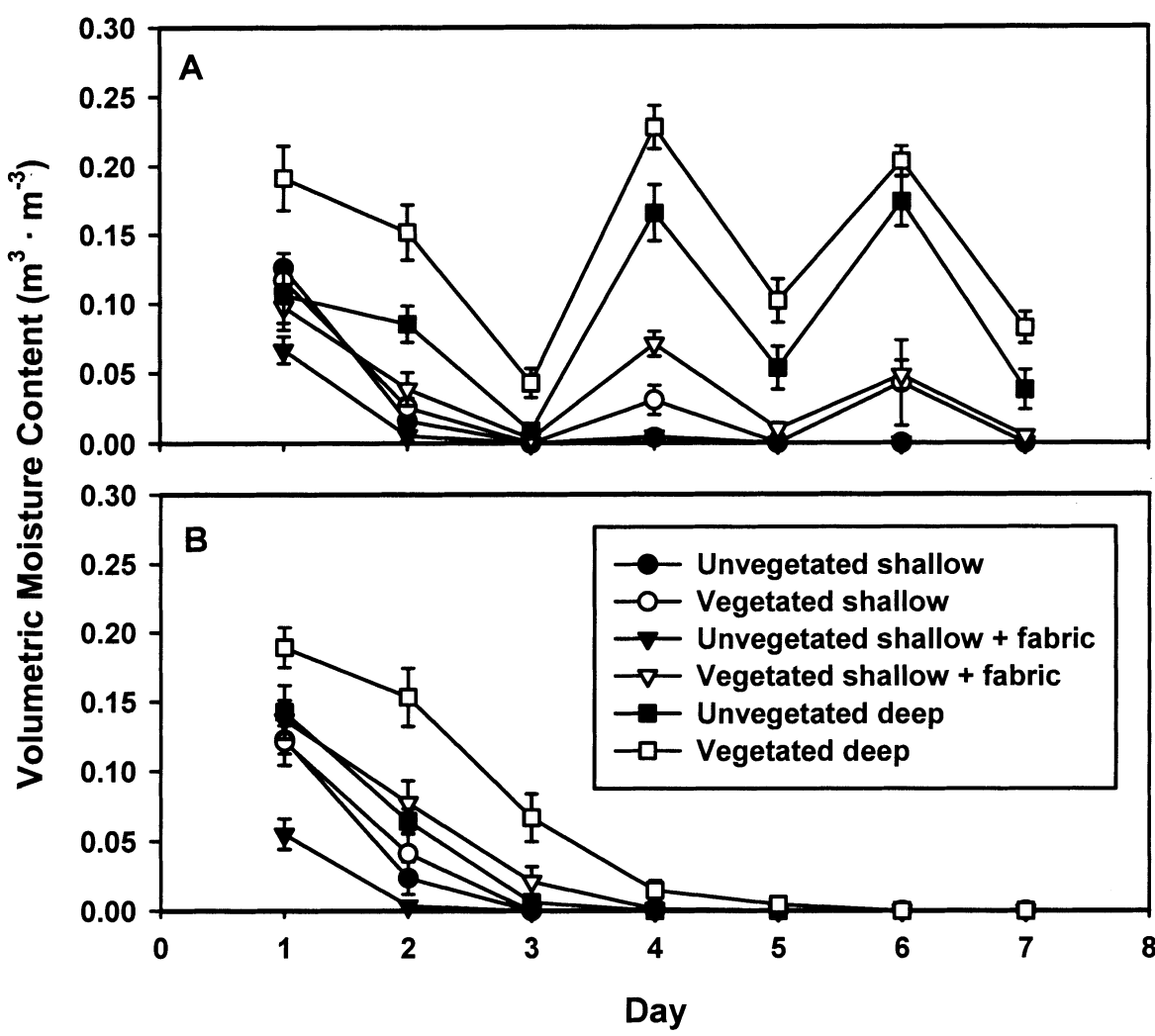

Fig. 2. Substrate volumetric moisture content $\left(\mathrm{m}^{3} \cdot \mathrm{m}^{-3}\right)$ over the first week of the study for watering regimes of $2 \mathrm{~d}$ between watering (DBW) (A) and 7 DBW (B). Data points represent unvegetated or vegetated substrate types of 1 ) shallow $=2 \mathrm{~cm}$ of media, 2) shallow + fabric $=2 \mathrm{~cm}$ of media with an extra moisture retention fabric layer, and 3 ) deep $=6 \mathrm{~cm}$ of media. Error bars represent standard error.

Following the establishment period, watering regimes of $2,7,14,28$, or $88 \mathrm{~d}$ between watering (DBW) were assigned randomly to each pot. Watered pots received $157 \mathrm{~mL}$ of water on designated days with excess water allowed to drain. Upon completion of the study after $88 \mathrm{~d}$, all shoots were destructively harvested and dried at $60{ }^{\circ} \mathrm{C}$ for $72 \mathrm{~h}$. The difference between the mean initial and final weights yielded a total shoot biomass production determination for each treatment.

Data collection. Alysimetric approach was used to measure water use over the course of this study. Before the first watering, pots were weighed to establish the dry weight of the pot, green roof components, dry media, sand-seed mixture, and fertilizer. On the first day of the study, pots were weighed after the initial watering; the difference between this weight and the dry weight reflected the water holding capacity of each pot. After the initial watering, pot weights were measured daily for the first week, then three times per week through week 4 , after which measurements were taken once per week for the remainder of the 12 week study. Substrate moisture was monitored throughout the study by inserting a theta probe (ML2x; Delta-T Devices, Ltd., Cambridge, U.K.) into the media until the points of the prongs contacted the vegetation carrier. Measurements were collected before watering on the same schedule as pot weights were measured. The theta probe instrument has a range of 0.0 to $1.0 \mathrm{~m}^{3} \cdot \mathrm{m}^{-3}$. It should be noted that the accuracy of the theta probe was \pm 0.01 $\mathrm{m}^{3} \cdot \mathrm{m}^{-3}$ for values from 0.05 to $0.6 \mathrm{~m}^{3} \cdot \mathrm{m}^{-3}$ and likely less for values below $0.05 \mathrm{~m}^{3} \cdot \mathrm{m}^{-3}$ and above $0.6 \mathrm{~m}^{3} \cdot \mathrm{m}^{-3}$ (Delta-T Devices, 1999).

Experimental design and statistical analysis. The experiment was a completely randomized design with two factors, substrate design and watering regime. The study consisted of three substrate types, five watering regimes, and an unvegetated control treatment to characterize plant water use. There were 10 replications of each treatment for a total of 300 pots. Pots were arranged with a single nonsampled border row consisting of vegetated and unvegetated control pots surrounding the study.

Shoot dry weight accumulation (final minus initial shoot dry weight) and percentage increase in shoot dry weight (final minus initial divided by initial shoot dry weight) were analyzed using an ANOVA model fitted with fixed effects of watering regime and substrate type. Although original means are presented, all differences were transformed prior to analysis using a log-linear hybrid transformation to stabilize the variance and normalize the data (Rocke and Durbin, 2003). Differences between treatments for shoot dry weight accumulation and percentage increase in shoot dry weight were analyzed using multiple comparisons with Tukey-Kramer adjustments (PROC MIXED, SAS version 8.02, SAS Institute Inc., Cary, N.C.).

Evapotranspiration (ET) values were derived from the repeated measurements of pot weights over the first week of study for watering regimes of 2 and $7 \mathrm{DBW}$ (7 DBW is representative of the other three watering regimes since none were watered over the first week). An estimate of the amount of water retained by each pot when watered was made based upon the pot weights before and after watering on the first day of study. Vegetated treatments within each of the two watering regimes were subjected to repeated measures analysis using an unstructured covariance structure (PROC MIXED). For substrate moisture analysis, all treatments were subjected to repeated measures covering the first $33 \mathrm{~d}$ of the study using an unstructured covariance structure (PROC MIXED). Values past $33 \mathrm{~d}$ were not used because the different watering regimes did not correspond to the days measurements were collected.

\section{Results and Discussion}

Shoot dry weight accumulation. Plants in all substrate compositions gained shoot biomass over the course of study when watered at least once every $7 \mathrm{~d}$ (Table 1). All substrate types accumulated more shoot biomass under the $2 \mathrm{DBW}$ regime compared to the other watering regimes $(P \leq 0.05)$. For both shallow substrates, the other watering regimes were not significantly different from each other. However, watering regime did influence plant growth in the deep substrate. Mean shoot dry weight accumulation was $2.63 \mathrm{~g}$ for the 7 DBW regime, followed by $14 \mathrm{DBW}(1.30 \mathrm{~g})$, $28 \mathrm{DBW}(0.99 \mathrm{~g})$, and $88 \mathrm{DBW}(-0.46 \mathrm{~g})$. All watering regimes were significantly different for the deep substrate except for the 14 and 28 DBW regimes. Data suggest that watering every other day is ideal for plant growth, but even those plants that experienced 88 straight days of drought still had plants alive at the end of the study.

Comparisons of shoot dry weight accumulation under different watering regimes between substrate types are also presented in Table 1. Plants in the deep substrate accumulated the most dry weight in the three most frequent watering regimes. However, it was not different from the other substrates under the 28 or 88 DBW regimes and was not different from the shallow + fabric substrate under the 14 DBW regime. Dry weight accumulation for both shallow substrates was not different under any watering regime. This suggests that the extra moisture retention fabric had minimal influence on plant growth.

Percentage increase in shoot dry weight. Values for the percentage increase in shoot dry weight mirrored those for shoot dry weight accumulation except for those plants grown under the 2 and 7 DBW regime (Table 2). Plants in the shallow $(674 \%)$ and shallow + fabric $(724 \%)$ substrates gained a higher percentage of biomass than those in the deep substrate $(374 \%)$. This is in contrast to the shoot dry weight accumulation data where plants in the deep substrate $(5.54 \mathrm{~g})$ grew more than those in the shallow $(1.82 \mathrm{~g})$ or shallow + fabric $(2.68 \mathrm{~g})$ substrates. Similarly, under the 7 DBW regime, plants in the deep substrate exhibited greater dry weight accumulation than the two shallow substrates, but the percentage increase was the same for all (Table 2). The greater percentage increases in the shallow substrates under the 
2 DBW regime can be attributed to the differences in initial dry weights. Mean initial shoot dry weights for plants grown in the shallow, shallow + fabric, and deep substrates were 0.27 , 0.37 , and $1.48 \mathrm{~g}$, respectively. Because the size of the initial plants were not equal across substrate treatments, it is necessary to compare percentage increases in order to make a direct comparison between treatments. However, one can still make the general statement that deeper substrates will result in greater growth.

It is also interesting to note, that in the deep substrate, the above ground biomass decreased $31 \%$ over the $88-\mathrm{d}$ study when compared to the initial dry weight (Table 2). This occurrence could be attributed to the larger vegetation found in the deeper substrate which had a higher water demand. Therefore, there was a greater amount of non-structural carbohydrates within the plants for potential degradation after the establishment period (Taiz and Zeiger, 1998).

Substrate moisture. Substrate moisture levels of the vegetated treatments were typically higher than those of unvegetated treatments in respective substrate designs. This is visible in watering regimes of $2 \mathrm{DBW}$ and 7 DBW ( $7 \mathrm{DBW}$ is representative of 14, 28, and 88 DBW over the first week) (Fig. 2). When viewed over the first 33 days of study (Fig. 3), the deep substrate treatments consistently had the highest substrate moisture value across all watering regimes on successive days. However, the deep vegetated treatments were only significantly different from the others under watering regimes of 2 and $7 \mathrm{DBW}(P \leq 0.05)$. The higher substrate moisture levels for the vegetated treatments are presumably due to the shade provided by the plant canopy which lowered substrate moisture evaporation. This agrees with Lohr and Pearson-Sims (2001) who reported that canopy closure reduced the need for irrigation of containerized 'Impulse Rose' impatiens (Impatiens wallerana L.). The spikes in the substrate moisture figures correspond with the watering that occurred according to the regimes assigned to the treatments.

Substrate moisture averaged across all treatments for the deep substrate was greater than either of the shallow ones. However, the shallow and shallow + fabric substrate moisture values were not different. Vegetated and unvegetated treatments averaged across all other factors were only different from each other under the $2 \mathrm{DBW}$ watering regime (data not presented). For substrate moisture comparisons within substrate design, the vegetated and unvegetated treatments were only different from each other for the deep substrate.

One particularly interesting result of the substrate moisture monitoring was how rapid the values dropped after water application.

Fig. 3. Substrate volumetric moisture content $\left(\mathrm{m}^{3} \cdot \mathrm{m}^{-3}\right)$ over the first $33 \mathrm{~d}$ of the study for watering regimes of (A) 2, (B) 7, (C) 14, (D) 28, and (E) $88 \mathrm{~d}$ between watering (DBW). Data points represent unvegetated or vegetated substrate types of 1) shallow $=2 \mathrm{~cm}$ of media, 2) shallow + fabric $=$ $2 \mathrm{~cm}$ of media with an extra moisture retention fabric layer, and 3) deep $=6 \mathrm{~cm}$ of media. Error bars represent standard error.



'E
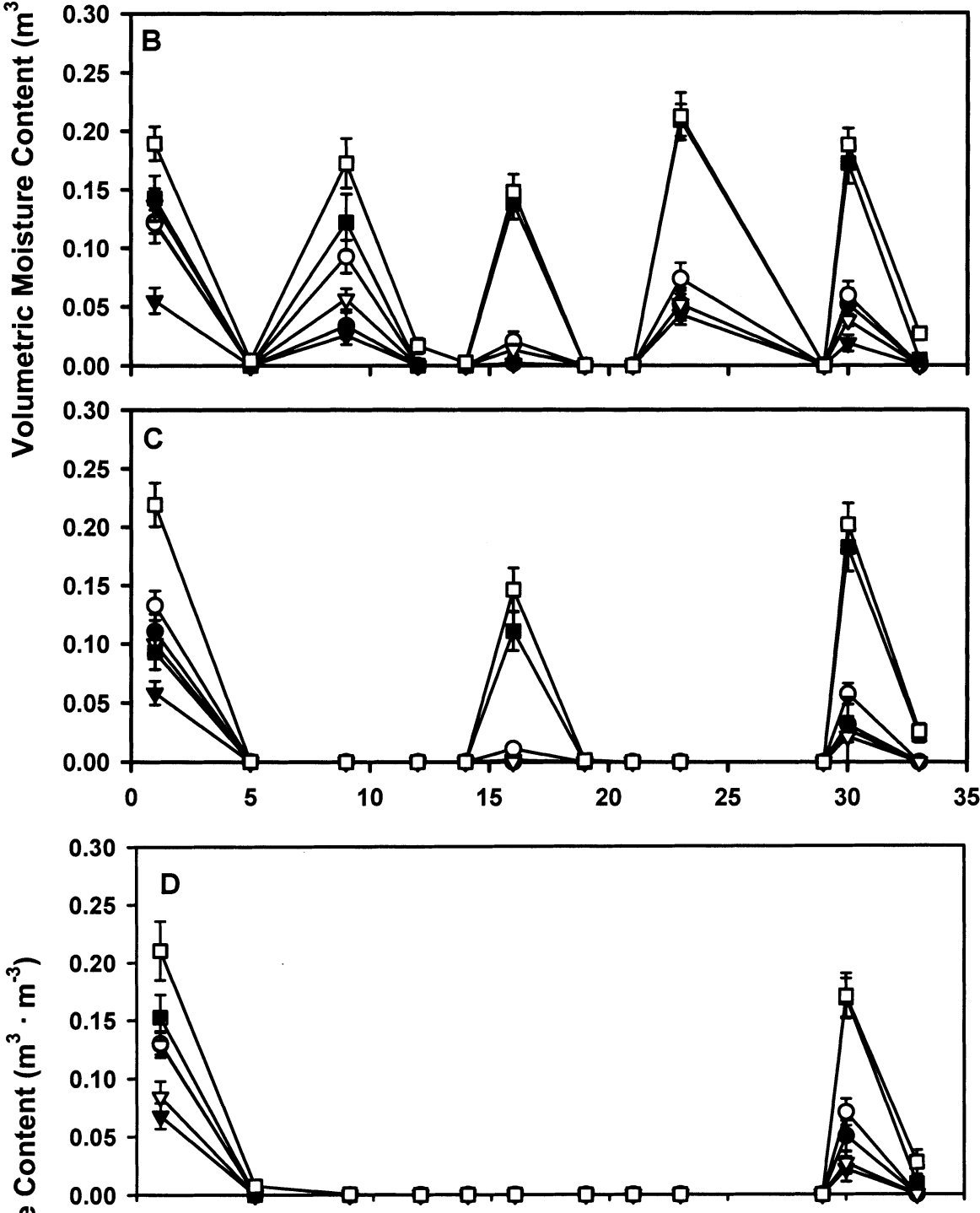

온

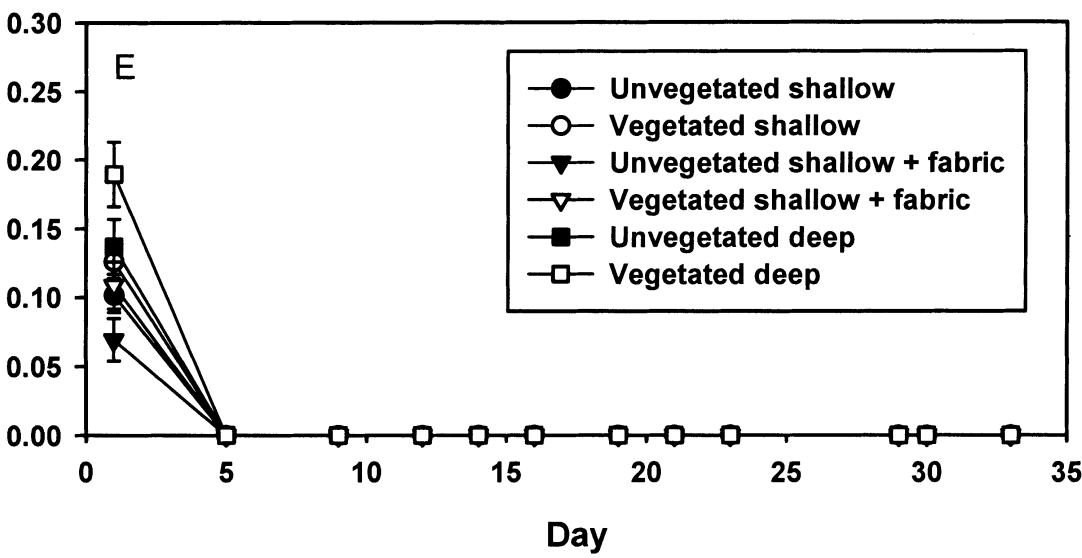



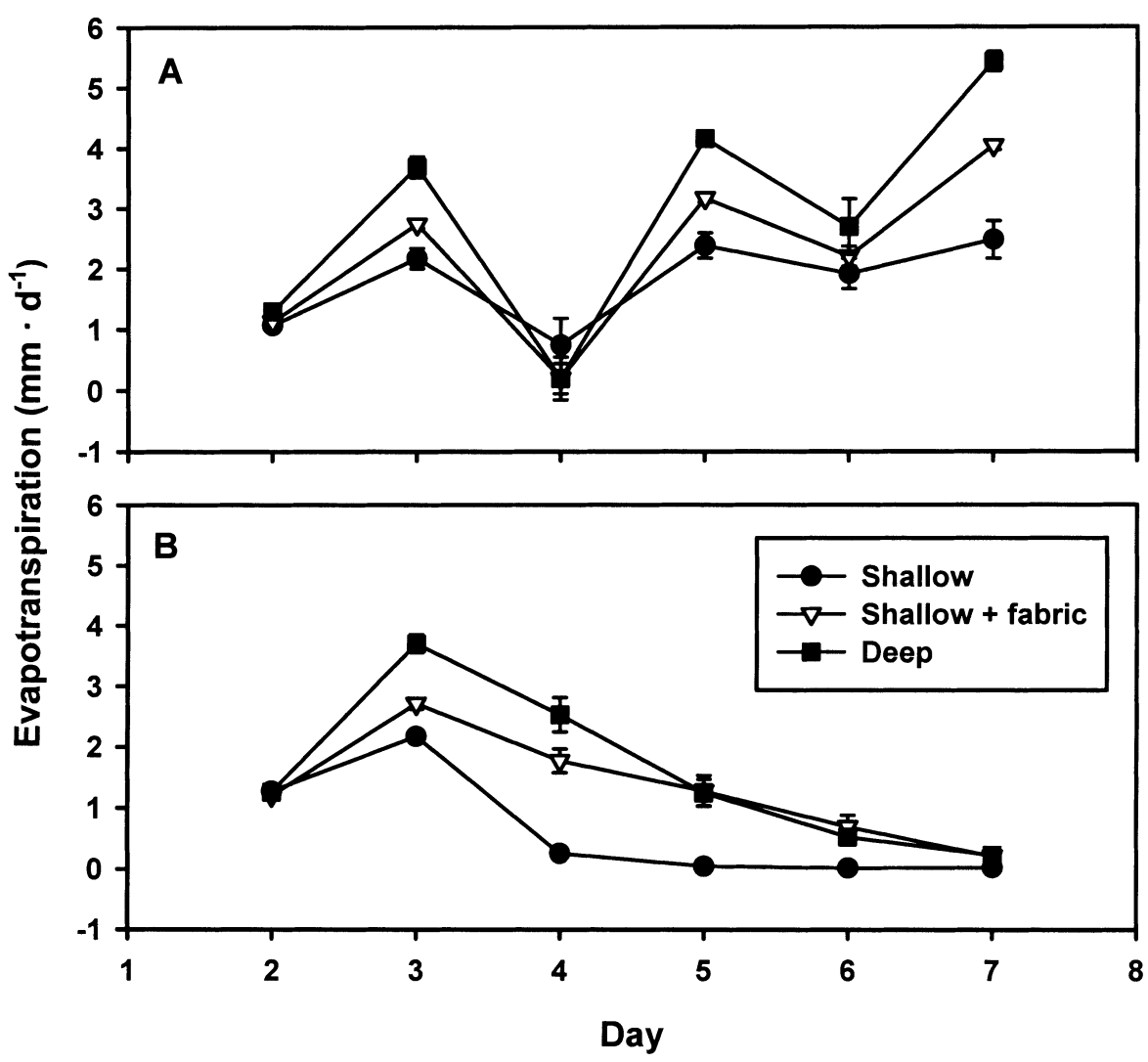

Fig. 4. Evapotranspiration values $\left(\mathrm{mm} \cdot \mathrm{d}^{-1}\right)$ over the first week of the study for watering regimes of $2 \mathrm{~d}$ between watering (DBW) (A) and 7 DBW (B). Data points represent vegetated substrate types of 1) shallow $=2 \mathrm{~cm}$ of media, 2) shallow + fabric $=2 \mathrm{~cm}$ of media with an extra moisture retention fabric layer, and 3) deep $=6 \mathrm{~cm}$ of media.

Depending on substrate type and whether or not it was vegetated, values dropped to $0 \mathrm{~m}^{3} \cdot \mathrm{m}^{-3}$ as quickly as one day after watering. For nonCAM plants growing in typical field soils, this would suggest a serious problem. However, Sedum spp. experience minimal adverse effects due to substrates with a low water holding capacity (Lassalle, 1998; Monterusso et al., 2005). Even so, substrate moisture values and plant growth would likely be lower in the small greenhouse pots than what might be present on a roof. One would expect that the much smaller volume of growing media in the pots would dry out faster. However, plants growing on a typical green roof would be exposed to much harsher environmental conditions.

Evapotranspiration. ET rates under the 2 DBW regime were highest on the day of watering. Second day rates were always lower than the preceding day. The ET rates of all treatments were significantly different on all watering days the first week (days 3,5 , and 7) (Fig. 4A). The deep substrate had the highest ET rate on all days except day 4, on which it was not significantly different from the other treatments. On the final day of measurement the first week, the shallow + fabric and deep substrates had ET rates significantly higher than any previously measured rate. This likely can be attributed to the ambient weather. Although air temperatures in the greenhouse were maintained at $21 \pm 1^{\circ} \mathrm{C}$ using a thermostat, air temperatures at times likely were higher due to solar heating. According to Prazak et al.
(1994), an increase in air temperature leads to an increase in potential ET.

After reaching a maximum ET rate on day 3 under the 7 DBW regime, ET for all substrates decreased daily until leveling off at $0 \mathrm{~mm} \cdot \mathrm{d}^{-1}$ (Fig. 4B). This occurred two days after watering for the shallow substrate and after seven days for the shallow + fabric and deep substrates. Although ET rates were at zero, the plants were still viable as determined from the results of Durhman et al. (2004) in which chlorophyll fluorescence was measured in a companion study that occurred simultaneously to the one reported here.

Overall, ET for the shallow + fabric and deep substrates was not significantly different under the 7 DBW regime, although the shallow substrate was different from both. On individual days, the shallow + fabric and deep substrates were only different on days 3 and 4 . However, by day 5 , their ET rates were essentially the same and by day 7 the ET rate of all substrates was essentially the same. The ET rates given for both regimes, 2 and 7 DBW, likely are rather conservative due to the conditions in which they were collected. Had this study been performed outdoors under additional climatic variables, mainly wind and increased solar radiation, ET rates would likely increase.

\section{Conclusion}

Although the vegetation of all substrate treatments survived after reaching ET rates as low as $0 \mathrm{~mm} \cdot \mathrm{d}^{-1}$, irrigation scheduling should be adjusted accordingly to prevent this during production or establishment. The primary goal during establishment is to achieve $100 \%$ coverage as soon as possible to inhibit weeds, reduce potential wind or water erosion, and to achieve the desired aesthetic qualities. However, irrigation is not as critical once vegetation is established. The ability of Sedum to withstand extended drought conditions makes it ideal for shallow extensive green roof systems. If an extensive green roof is to be truly sustainable and not depend on supplemental irrigation, then it must tolerate all the harsh conditions presented, including extended periods of drought. Most Sedum spp. fulfill these requirements.

The deepest substrate treatment $(6 \mathrm{~cm}$ of media), clearly performed the best in terms of substrate moisture retention and plant growth. The greater percentage increase in shoot dry weight for the shallow substrates under the frequent watering regime was somewhat misleading because of the lower initial dry weights of those plants. The deeper substrate did not dry out as fast, so a greater amount of water was retained and available to the plants during periods of drought. Because of the fact that many Sedum spp. are not always negatively affected by drought, the vegetation in shallower substrates may perform equally as well once substrate moisture has lowered to 0 when the vegetation has been installed on a roof. One method to extend the period of water availability to the plant is to utilize water retention fabric under the substrate. Although our results suggest that it is not necessary for green roof vegetation in the propagation stage, once the vegetation is placed on a roof the fabric would help mitigate the effects of drought. Even so, plants of Sedum subjected to drought for the duration of the study $(88 \mathrm{~d})$ were still viable at the end of the experiment.

\section{Literature Cited}

Boivin, M., M. Lamy, A. Gosselin, and B. Dansereau. 2001. Effect of artificial substrate depth on freezing injury of six herbaceous perennials grown in a green roof system. HortTechnology 11(3):409-412.

Borland, A.M. and H. Griffiths. 1990. The regulation of CAM and respiratory recycling by water supply and light regime in the $\mathrm{C}_{3}$-CAM intermediate Sedum telephium. Funct. Ecol. 4:33-39.

Delta-T Devices, Ltd. 1999. ThetaProbe Soil Moisture Sensor Type ML2x user manual. Delta-T Devices, Cambridge, U.K.

Dimoudi, A. and M. Nikolopoulou. 2003. Vegetation in the urban environment: microclimatic analysis and benefits. Energy Build. 35:69-76.

Dramstad, W.E., J.D. Olson, and R.T.TForman. 1996. Landscape ecology. Principles in landscape architecture and land-use planning. Harvard Univ. Graduate School of Design-Island Press-Amer. Soci. Landscape Architects, Wash., D.C.

Dunnett, N. and N. Nolan. 2004. The effect of substrate depth and supplementary watering on the growth of nine herbaceous perennials in a semi-extensive green roof. Acta Hort. 643:305-309.

Durhman, A., N.D. VanWoert, D.B. Rowe, C.L. Rugh, and D. Ebert-May. 2004. Evaluation of Crassulacean species on extensive green roofs. 
Proc. 2nd N. Amer. Green Roof Conf.: Greening Rooftops for Sustainable Communities 2:504-517.

Gravatt, D.A. and C.E. Martin. 1992. Comparative ecophysiology of five species of Sedum (Crassulaceae) under well-watered and drought-stressed conditions. Oecologia 92:532-541.

Gurevitch, J., J.A. Teeri, and A.M. Wood. 1986. Differentiation among populations of Sedum wrightii (Crassulaceae) in response to limited water availability: water relations, $\mathrm{CO}_{2}$ assimilation, growth and survivorship. Oecologia 70:198-204.

Herman, R. 2003. Green roofs in Germany: yesterday, today and tomorrow. Proc. 1st N. Amer. Green Roof Conf:: Greening Rooftops for Sustainable Communities 1:41-45.

Kirschstein, C. 1997a. Die dürreresistenz einiger Sedum-arten. Abgeleitet aus der Bedeutung der Wurzelsaugspannung-Teil 1. Stadt und Grün . 46(4):252-256.

Kirschstein, C. 1997b. Die dürreresistenz einiger Sedum-arten. Abgeleitet aus der Bedeutung der Wurzelsaugspannung-Teil 2. Stadt und Grün. 46(6):434-439.

Lassalle, F. 1998. Wirkung von trockenstre $\beta$ auf xerophile pflanzen. Stadt und Grün. 47(6):437-443.

Lee, K.S. and J. Kim. 1994. Changes in crassulacean acid metabolism (CAM) of Sedum plants with special reference to soil moisture conditions. J. Plant Biol. 37(1):9-15.
Liesecke, H.J. 1998. Das retentionsvermögen von dachbegrünungen. Stadt und Grün. 47(1):46-53.

Liesecke, H.J. and H. Borgwardt. 1997. Abbau von luftschadstoffen durch extensive dachbegrünungen. Stadt und Grün. 33(5):245-251.

Liptan, T. 2003. Planning, zoning and financial incentives for ecoroofs in Portland, Oregon. Proc. 1st N. Amer. Green Roof Conf.: Greening Rooftops for Sustainable Communities 1:113-120.

Lohr, V.I. and C.H. Pearson-Mims. 2001. Mulching reduces water use in containerized plants. HortTechnology 11:277-278.

Monterusso, M.A., D.B. Rowe, and C.L. Rugh. 2005. Establishment and persistence of Sedum spp. and native taxa for green roof applications. HortScience 40:391-396.

Monterusso, M.A., D.B. Rowe, C.L. Rugh, and D.K. Russell. 2004. Runoff water quantity and quality from green roof systems. Acta Hort. 639:369-376.

Niachou,A., K. Papakonstantinou, M. Santamouris, A. Tsangrassoulis, and G. Mihalakakou. 2001. Analysis of the green roof thermal properties and investigation of its energy performance. Energy Build. 33(7):719-729.

Prazak, J., M. Sir, and M. Tesar. 1994. Estimation of plant transpiration from meteorological data under conditions of sufficient soil moisture. J.Hydrol. 162(3-4):409-427.

Relf, P.D. and V.I. Lohr. 2003. Human issues in horticulture. HortScience 38(5):984-993.
Rocke, D.M. and B. Durbin. 2003. Approximate variance-stabilizing transformations for geneexpression microarray data. Bioinformatics 19(8):966-972.

Rowe, D.B., C.L. Rugh, N. VanWoert, M.A. Monterusso, and D.K. Russell. 2003. Green roof slope, substrate depth, and vegetation influence runoff. Proc. 1st N. Amer. Green Roof Conf.: Greening Rooftops for Sustainable Communities 1:354-362.

Staats, D. and J.E. Klett. 1995. Water conservation potential and quality of non-turf groundcovers versus kentucky Bluegrass under increasing levels of drought stress. J. Environ. Hort. 13(4):181-185.

Taiz, L. and E. Zeiger. 1998. Plant physiology. 2nd ed. Sinauer Assoc., Sunderland, Mass.

Teeri, J.A., M. Turner, and J. Gurevitch. 1986. The response of leaf water potential and crassulacean acid metabolism to prolonged drought in Sedum rubrotinctum. Plant Physiol. 81:678-680.

Ting, I.P. 1985. Crassulacean acid metabolism. Annu. Rev. Plant Physiol. 36:595-622.

VanWoert, N.D, D.B. Rowe, J.A. Andresen, C.L. Rugh, R.T. Fernandez, and L. Xiao. 2005. Green roof stormwater retention: Effects of roof surface, slope, and media depth. J. Environ. Quality 34:1036-1044.

Wong, N.H., Y. Chen, C.L. Ong, and A. Sia. 2003. Investigation of thermal benefits of rooftop garden in the tropical environment. Build. Environ. 38:261-270. 